22
$A 84$ UC - NRLF

||||||||||||||||||||||||||||| |||||||||| "Minimiminat $\begin{array}{lll}5 & 30 & 36\end{array}$ 


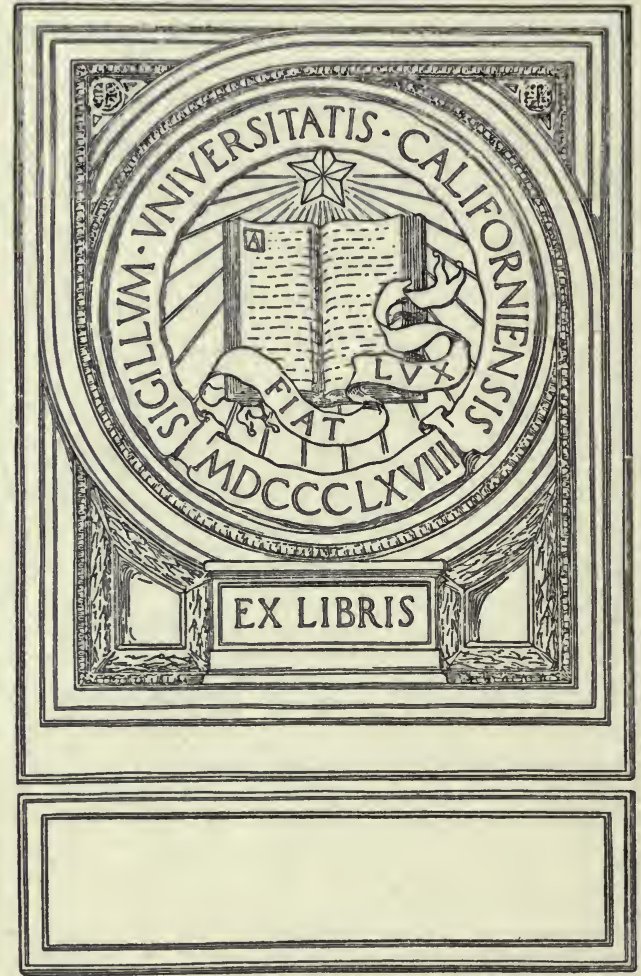



Digitized by the Internet Archive in 2007 with funding from Microsoft Corporation 


\section{Association if of Lowetgiant colteg of \\ American Agricultural Colleges}

and

\section{Experiment Stations}

Report of the Executive Committee

on the

Amendment of the Constitution

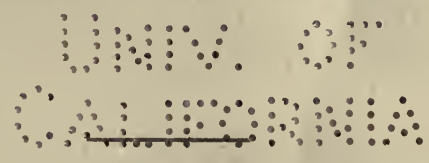

Berkeley, California

August 11th, 12th, 13th, 1915 


$$
s^{2} a^{2} k
$$




\title{
Report of the Executive Committee
}

\author{
$-\mathrm{nth}$ \\ Amendment of the Constitution
}

To the Association of American Agricultural Colleges and Experiment Stations, in session at Berkeley, California, August 11-13, 1915:

At the last meeting of this Association the following action was taken:

"Moved, that the Executive Committee be requested to poll the membership of the Association on the question: What changes would you suggest in the Constitution and methods of organization of this Association; and further, that the Committee after this canvass is completed, report its own conclusions upon the question and make such recommendations of changes in the Constitution of the Association, or such other steps, as it may regard as necessary or desirable in order to carry out its conclusions."

Pursuant to this action the Executive Committee addressed a letter under date of May 22, 1915, to the several colleges and stations, calling attention to the several motions and discussions as reported in the Proceedings and to the action taken. Separate printed copies of the Constitution were forwarded with the letter and request made for replies in order that the Executive Committee might have the data desired for a report.

Exclusive of those represented by members of the Executive Committee, sixteen institutions responded. From one institution three men wrote expressing three different points of view. Four presidents responded. Twelve deans or directors and three Extension officers responded. Obviously less than half the Institutions replied. There was no such general response on the part of the officers as would intimate to the Executive 
Committee any preponderating sentiment one way or the other. At most, one-half of the votes could be counted as favoring in a general way the amendment proposed. About one-third were opposed and some responses made new proposals without committing the authors definitely to any program. In general it may be said that the method proposed by the resolution above cited brought to the Executive Committee very little information or guidance. After correspondence and some discussion at a meeting held in Washington, June 30th, it was agreed that the Chairman of the Committee should prepare a report and print it for distribution at the meeting, August 11th.

This report is therefore submitted with a definite understanding that the Chairman alone is to be held responsible for its contents since it was impracticable to submit it for amendment and approval to the several members.

\section{Some Historical Data.}

The Honorable Norman J. Colman, Commissioner of Agriculture under date of May 6th, 1885, issued a call for the first convention which assembled in Washington July 8, 1885. At this convention there were present representatives of the Department of Agriculture, Boards of Agriculture, the Agricultural Press, persons representing agriculture in foreign countries, the Agricultural Colleges, the Experiment Stations and individual delegates representing agricultural interests, in all seventy-eight persons. This convention of delegates made provision for perpetuating the existence of the body not yet organized under a definite plan.

In the proceedings of the Second Annual Convention of the Association of American Agricultural Colleges and Experiment Stations held at Knoxville, Tenn., January 1, 2, and 3, 1889, there appears a brief Constitution. In the Proceedings of the third Annual Convention held in Washington, November 12-15, 1889, the Constitution appears with an amendment providing for permanent committees. The following sentences are quoted from the Constitution: "The Association shall be organized into permanent committees upon the several classes of special subjects, the consideration of which shall become desirable. Provision shall be made in the programme for conferences of each of the Committees, either simultaneously or consecutively as the Execu- 
tive Committee shall determine." There shall be permanent Committees on agriculture, on botany, on chemistry, on entomology, and on horticulture; and the Executive Committee, upon request of any five institutions represented in the Association shall provide for the organization of a new Committee at any Convention."

In the Proceedings of the Fourth Annual Convention, held at the University of Illinois, November 11-13, 1890, the Constitution appears with the paragraph on permanent Committees amended with the title "permanent Committees" changed to "Sections" with appropriate changes in the phraseology and a section on "College work" is added.

In the Proceedings of the Sixth Annual Convention, held at New Orleans, November 15-19, 1892, the Constitution appears with amendments as follows:

1. The Association shall be organized into sections upon (1) College work; (2) Agriculture and Chemistry; (3) Horticulture and Botany; (4) Entomology; (5) Mechanic Arts. The Executive Committee shall, upon the request of any ten institutions represented in the Association, provide for the organization of provisional sections at any convention.

2. Each section shall conduct its own proceedings and shall keep record of the same, and present a synopsis thereof to the Association at the close of every Convention; and no action of a section, by resolution or otherwise, shall be valid until the same shall have been ratified by the Association in general session.

It would interest members of the Convention to read the debate on the amendment introduced by the President, J. K. Patterson, of Kentucky, providing for a section on Mechanic Arts, inasmuch as a separate Association was then under discussion. See Proceedings of the Sixth Convention, page 74 .

In accordance with the above amendment to the Constitution, the first annual meeting of the section on Mechanic Arts was held with the Association at Chicago, in October, 1893. In the Proceedings of the Association for the meeting at Denver, Colorado, July 16-18, 1895, page 18, there appears the following report from the section on Mechanic Arts:

"During the past year an effort has been made to develop, practically, but one side of the Section on Mechanic Arts, viz., the correlation of mechanic arts and agriculture. 
The Society for the Promotion of Engineering Education covers the broader field of engineering, and we believe that our range of work in this Association should be a limited one.

By well-directed efforts the Section on Mechanic Arts can be made a valuable adjunct to the agricultural side of this Association by bringing more intimately in contact the agricultural and mechanical work in the colleges.

We believe that some steps should be taken to send at least one delegate from the colleges of the Association to represent the mechanical side of our institutions, but if such a move is to be made the agriculturalists must take the initiative.

Most of our men interested in mechanic arts are indifferent toward doing work for the Association, claiming that the Association is essentially agricultural and it is the intention of the agriculturalists to keep it within such limits."

In the report from the section on Mechanic Arts presented at the Tenth Annual Convention, Washington, November 10-12, 1896, (see Proceedings, pages 26-28), there appeared this paragraph: "Many of the professors in the mechanical departments have expressed themselves as being very desirous of attending these meetings and exchanging ideas with their fellow workers. Why are they not present the same as the professors from the other college departments? Could not this be brought about? Can not the College presidents and trustees present see to it that more of the mechanical men are present at these meetings?

The following extract is taken from the Proceedings of the Eleventh Annual Convention, held at Minneapolis, July 13-15, 1897. See page 28 for full report:

"At the Tenth Annual Convention of this Association, held at Washington, D. C., November 1896, a special Committee was appointed "to revise the Constitution of the Association and report at the next Annual Convention." The Committee thus appointed, having considered the subject assigned, begs leave to submit the following report:

"The members of the Committee have discussed this important matter among themselves, and have obtained the opinion of a number of gentlemen heretofore active in the work of the Association whom it has been convenient to consult. A considerable diversity of opinion has been developed as to the most 
useful form for the Association to take to accomplish its future work, and it seems expedient to present two different propositions.

A majority of the Committee and of those whom it has been practicable to confer with favor a radical change in the Constitution, and this is first submitted for consideration and action.

This plan proposes the abolition of all sections, so that if adopted, the Annual Convention of the Association would thereafter be a meeting of the Executive Officers of Colleges and Stations, with such other and special delegates as the institutions respectively saw fit to send to these conferences.

It is believed by those favoring this plan that it will effectively bring the Association back to its original purpose, namely, the consideration in annual conference of the problems of College and Station administration, as affecting (a) internal working, (b) relations of the government of the United States, (c) relations to the state governments respectively, (d) relations to other institutions, and (e) attitude toward new legislation proposed from time to time.

The delegates who are able to assemble annually as representatives of the institutions forming the Association need the entire time at their disposal, to enable them to give undivided attention to these subjects of paramount importance.

If the sections are continued, the natural tendency will be to increase the number, because, if it is good policy to have any departments of colleges and stations represented by specialists, it is expedient and right that all departments should have equal opportunities. Following this logical course, it will be more and more difficult than it now is to select and limit the attendance at these conventions.

There are, however, other organizations of chemists, engineers, botanists, etc., which professors and investigators desire to attend at which they have ample opportunities for the work they now seek to do at the conventions of this Association, and where for many reasons, it is better for them to go. At these other meetings delegates from the various land-grant colleges and experiment stations come in contact not only with men from institutions of like character, but also with men from all the other colleges and universities and technical schools. This opens a wider field and presents superior advantages. Many believed that, forced on economical grounds to make choice, the institutions concerned 
and their workers will decide that their time and money can be more profitably used by attendance at these larger and more general gatherings than at the special meetings of this body."

At the Twelfth Annual Convention, in Washington, November $15-17,1898$, the proposed amendments were discussed at two sessions and the proposals defeated by a vote of forty-four to eight. Members are referred to this report, pages 46 and 54, for a good summary of the conditions existing and for an illuminating discussion by experienced members of the Association.

Before adjournment at San Francisco a "Committee on the revision of the Constitution" was appointed. This Committee reported at the Fourteenth Annual Convention, held at New Haven, November 13-15, 1900, with but two amendments, one referring to the programme and one to membership. The article on membership as proposed read as follows; the italics being the amendment: "Every college established under the act of Congress approved July 2, 1862, or receiving the benefits of the act of Congress, approved August 30, 1890, and every department of mechanic arts so established, and every agricultural experiment station, etc.

Action on this amendment was taken at the Fifteenth Annual Convention, held in Washington, November 12-14, 1901 . See Proceedings, page 50. This action struck out the proposal to give representation to the department of mechanic arts, evidently on the theory that institutions and not departments should have representation. The section on mechanic arts was continued as before. On pages 38-40 of the Proceedings for 1901 will be found an admirable report on the scope of the work for the section in mechanic arts by $\mathrm{H}$. W. Tyler, Chairman of the Section for that year.

At the Sixteenth Annual Convention, Atlanta, Georgia, October 7-9, 1902, a proposal to amend the constitution was made. See Proceedings of 1902, page 44 . The proposed amendments provided for two sections. (1) A Section on College Work and Administration; (2) A Section on Experiment Station Work. The amendments proposed provided further that each section might create such divisions as it may from time to time find desirable.

At the Seventeenth Annual Convention, in Washington, November $17-19,1903$, the amendments were adopted by a vote 
of 53 to 1. From this time on no further mention appears of mechanic arts in the programme of the Association. By a series of amendments to the Constitution there disappeared the sections on agriculture and chemistry, on horticulture and botany, on entomology and on mechanic arts. It would appear that the Association had through a series of years with no little debate steadily developed into a Convention of Administrative Officers in which the two great interests were the Colleges of Agriculture and the Experiment Stations.

In stating this conclusion as of the date of 1903 , it should be noted that repeatedly there was represented to the Association the need of Engineering Experiment Stations and that at one time the Association expressed its preference between two bills favoring the one for Experiment Stations.

At the Twenty-second Annual Convention, held in Washington, November 18-20, 1908, (see Proceedings, page 44), a proposal to amend the Constitution by having a section on the Extension Work, was announced. In the subsequent year at the Portland meeting of the Association in 1909, the section on Extension Work was adopted and is now a part of the Constitution.

Subsequently a new Association was organized known as the Land Grant College Engineering Association. This has now been in active operation for a period of three years and is holding its fourth Session during the current week. The question is now raised whether this Association should continue as a separate and distinct association or whether it should be recognized as a division of the parent Association on the same basis as the Colleges of Agriculture, Stations and Extension Division.

It may be worth while to direct the attention of the Association to the fact that the Act of 1862 recognizes the Colleges of Agriculture and Mechanic Arts. It does not recognize separate Colleges of Agriculture or separate Colleges of Mechanic Arts. The division into Agricultural and Mechanic Arts is an administrative convenience as constituted in separate institutions. In some of the states like Iowa, Michigan and others, these institutions have the subdivisions known as Agricultural and Mechanic Arts, whether called schools or colleges or divisions, is not vital. In other institutions like Illinois and Ohio, the universities have a number of colleges or schools where agriculture is given a separate administration, as is also Mechanic Arts, usually under the title 
of Engineering. These colleges are on the same basis as colleges of Law, Medicine or other administrative devices, but are to be regarded as subdivisions of the institutions whether known as College or University.

The Experiment Stations were provided for in the Hatch Act, by a separate Act of Congress, which said: "There shall be established, under direction of the College or Colleges or Agricultural Department of Colleges, $* * * *$ a department to be known and designated as an 'Agricultural Experiment Station.' " In section eight of the Act, provision was made by which a state might have an agricultural experiment station separate from the agricultural colleges and under separate management. Some states have taken advantage of this provision. This situation has probably given rise to the confusion over the term "institution" since evidently a separate station would be regarded as an institution, while a station organized as a department of the College of Agriculture or Mechanic Arts, might not be so construed.

In the development of the proposed organization it might be well, therefore, to recognize that fact that the Engineering Divisions are not separate institutions and that it would be well to cling to the legal term "Mechanic Arts" since this term has been interpreted by this Association to include all types of Engineering. The mere academic question as to the relation between Mechanic Arts and Engineering may be left for leisurely discussion, but it would seem well for the Association to use the legal terms as provided in the Acts of Congress, leaving the interpretation of these terms as a matter of detail.

It may further be remarked that since Home Economics has been definitely named in the Smith-Lever Bill, certain persons are disposed to regard that as a warrant for a section on Home Economics. It may be suggested, however, that the object of the Smith-Lever Bill was to provide for Agricultural Extension, under which term Home Economics was but one of the specifications. It is doubtful therefore, whether a section on Home Economics could be justified any more than sections on other subjects specifically named in the second Morrill Act.

In giving this subject consideration it may be well to cast a look forward. There is good reason to believe that Congress will sooner or later provide for Engineering Experiment Stations. 
This Association has repeatedly endorsed the proposal. Some institutions in the country have already established and organized these stations. This is following the precedent by which certain Agricultural Experiment Stations were established prior to the Hatch Act. When such stations are provided for by law we shall know whether they are to be regarded like the Agricultural Experiment Stations as subdivisions of the Colleges of Agriculture and Mechanic Arts or whether they are to be separate institutions under separate form of government. In no case could they be subdivisions of a College of Engineering, since these Colleges are not legal entities, but administrative subdivisions of Colleges or Universities, although it will be freely granted that their management would be under the direction of the teachers of Mechanic Arts or Engineering just as now the Agricultural Experiment Stations are chiefly under the direction of the men engaged in agriculture.

The Association therefore seems to be confronted with one or two policies; first, to go back to the original idea of a Convention representing the Colleges organized under the Act of 1862, with subdivisions to be known either as Committees or Sections, including all of the activities of these institutions or so many of them as the Association may decide. Reference to this report will disclose the fact that the Association has changed its mind from time to time on this matter. The Committees on Botany, Horticulture, and others have disappeared. The reason evidently was that men engaged in scientific work preferred to have their affiliations with scientific associations and could not well take the time to attend both classes of organizations. It may be pertinent to suggest that the movement over the entire country toward the development of all sorts of scientific, administrative and educational organizations and conventions makes a very heavy draft upon the institutions. Teachers feel that they cannot afford to pay their own expenses to all these conventions and the institutions feel that they cannot afford to have so many men absent from their ordinary duties for as much time as is necessary to meet the demand for attendance. Besides, the matter of expense is not inconsiderable. Reference to this report will show that experience demonstrated that the Engineering men were not made delegates to this Association with sufficient frequency and regularity to give a section on Mechanic Arts the dignity 
and strength in the Association to which the work was entitled. The Association is now considering whether it shall increase the number of delegates by multiplying the Sections or Committees so as to have practically two hundred or more men from these institutions assemble every year in convention.

Second: The other proposal is to create sections on a practical equality, each one of which will be recognized substantially as an institution, namely, the College, the Station, the Extension Division, and the Mechanic Arts or Engineering Division. The theory on which this has proceeded is that these subjects are of large administrative importance. If we eliminate particular subjects and confine the convention to administrative divisions, the Association would then become a body of administrative officers attended by Presidents, Deans, Directors, Superintendents, or by whatever other title the administrative officers of these institutions would be designated.

The logical result of this second method would be to recognize the parity of this subdivision. The opinion is here expressed that a good many people act upon the theory that Mechanic Arts is an administrative division on a parity with Agriculture and that both of them somehow should be recognized as institutions. The fact is that the law does not recognize any such division. The Smith-Lever Act also recognizes that Extension Service is a subdivision of the institutions founded under the Act of 1862 .

Reference to the discussions that have taken place in this Association as reported in the Proceedings from year to year will disclose the fact that a considerable proportion of the men attending this convention for the last twenty years has been disposed to recognize the Stations as separate institutions and thus to have in their mind two divisions, namely, the College and the Station. There is some justification for the belief that this Association has shown a tendency to regard itself as exclusively Agricultural and to ignore the division of Mechanic Acts. The success before Congress in passing distinctive Agricultural measures has given rise to the belief that the Association's endorsement of engineering measures, while sincere has not carried with it the same sort of activity in their support as has characterized its endorsement of distinctly agricultural proposals. The men representing Mechanic Arts or Engineering believe that the 
Federal aid should come to this division of the work in due time. They have not been opposed or indifferent to the appropriations for agricultural purposes, but they believe sincerely that an aggressive movement should be started looking toward Federal aid for engineering experiment stations and for engineering extension work. This will raise the question sooner or later whether a new section on engineering extension work shall be provided within this Association. The fact that in some states the universities and colleges of agriculture are separate has developed a situation as to mechanic arts and engineering that may make it impossible ever to secure Federal aid for mechanic arts or engineering. It certainly becomes important that this Association should face that problem and face it squarely. This is infinitely more important than the technical question of amending the Constitution. If the agricultural portion of the Association is at heart opposed to Federal aid for the mechanic acts work and to the development of money for extension in mechanic arts parallel to the work in the Smith-Lever Bill, that fact should be frankly and publicly stated. The truth is that some states are now spending considerable revenue in general university extension. In the future they probably will expend more. It is worth while to consider whether these so called Land Grant Colleges together with such of the state universities as have been developed around the College of Agriculture and Mechanic Arts, as in Ohio, for example, shall by a close co-operation develop teaching as represented in the College, research as represented in the Experiment Stations, for both Agriculture and Engineering and Extension Work as represented by Agriculture and Mechanic Arts or whether they shall allow this general field to be ignored or neglected. Possibly it may not be neglected, but these institutions will eventually be held responsible for the organization of all these scientific and educational activities.

Attention may now be directed to the fact that every year a considerable number of Associations more or less technical and scientific in character meet at the same time and place as this Association. Reference to the programme will find several of these organizations announced this year. It is evident that these societies are composed chiefly of men associated with the United States Department of Agriculture, Bureau of Education and the group of Colleges represented in this Association. Whether 
all these organizations ought to be federated in a great national convention because they represent public national interests, is in the minds of many a somewhat important question. This would make necessary the discussion of scientific, technical, and educational questions rather than administrative questions and problems of public policy. While it is perfectly obvious that this Association has tended toward the administrative character, it is equally obvious that Associations for the discussion of scientific and educational questions have continued to develop. It is also true that the programme of this Association has shown a decided preference for the administrative feature. Reference to the Proceedings for 1914, page 233 and 234, will disclose some keen criticism of the programme for including what might be termed technical papers. In view of all these tendencies it would seem that the Association should regard its future as administrative and make its organization accordingly. Any other policy involves a complete revolution and a new organization.

Conclusion: In view of the considerations reported above, the Chairman, speaking for the Executive Committee without formal approval, suggests that the Association should not at this time undertake to amend the Constitution in a specific way. On the other hand the Committee believes that it would be well for the Association to settle by vote the general issue as to the policy the Association represents. In determining this question the opinion is expressed that the Association should keep in mind whether the future is to involve the question of Engineering Experiment Stations and Engineering Extension Service as well as Agricultural Experiment Stations and Agricultural Extension Work. This would make at least five sections in the Association. It will be recalled that the Association made provision for a Committee on Agricultural Extension Work before the passage of the Smith-Lever Act. Reference to the Proceedings will also show that the original idea of extension work was rather limited and meager in 1905, but that the idea steadily developed through the several reports presented to the Association and now is a matter of incomplete statement. There is no good reason, therefore, why the Association should not now make provision for Engineering Extension Service provided the separate organization of the Mechanic Arts or Engineering Division, now known as the Land Grant College Engineering Association, is not to be 
continued, but to be included in the work of this Association. The purpose of this report is to bring before the Association a brief account of its own experiences, to intimate what its own positions have been and to present the issue now raised by the proposed affiliation or absorption of the Land Grant College Engineering Association. There is no need of further amendment unless that organization is to be included in this Association. If it is to be included, then the Constitution should be re-written on the basis of the Act of 1862 and provision made for a Convention of these institutions that should deal chiefly with administrative problems. The history of the Association goes clearly to show that discussion of scientific and technical questions has been referred to scientific and technical organizations. The Committee therefore recommends that the Association settle by vote the one question of policy and then refer the matter of amending or re-writing the Constitution to the Executive Committee or to a special Committee appointed for that purpose as seems best.

Respectfully submitted,

W. O. Tномpson,

Chairman Executive Committee. 



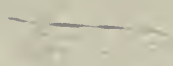

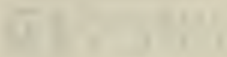




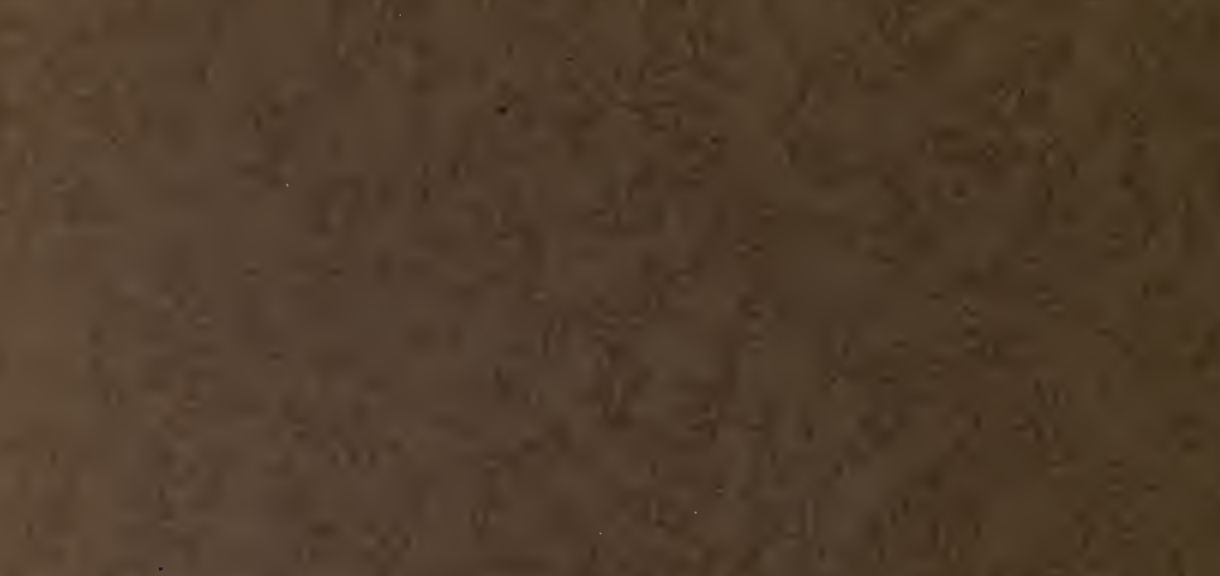

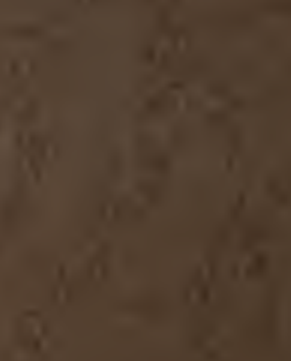

$+4$

$1-7+2 x+6$

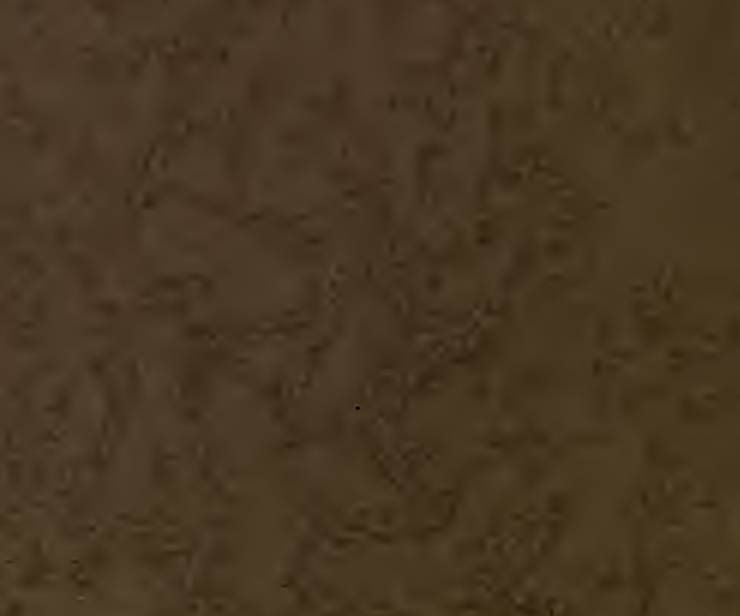

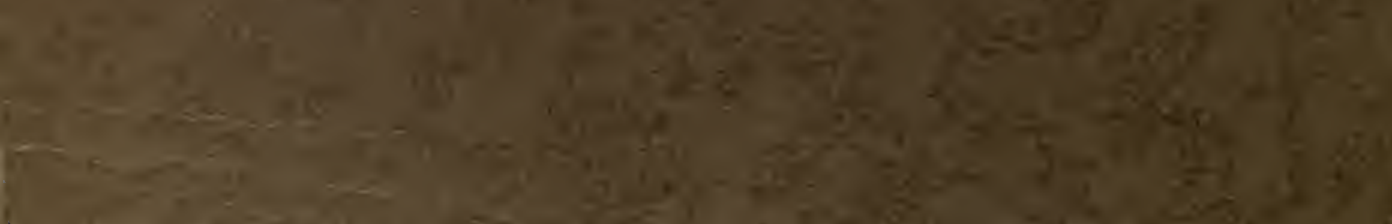

